\title{
Biblioteconomia: aspectos da formação bibliotecária no contexto brasileiro
}

\author{
Alline Heloise Valle Paiva \\ Graduanda em Biblioteconomia da Universidade Federal do Rio Grande do Norte (UFRN). \\ E-mail: rosamilena3@gmail.com \\ Jacqueline de Araujo Cunha \\ Professora Adjunta do Departamento de Ciência da Informação da Universidade Federal do Rio Grande \\ do Norte (UFRN). \\ Mestre em Ciência da Informação pela UFPB. \\ E-mail: jacquelinecunh@gmail.com \\ Jéssica Souza Martins \\ Graduanda em Biblioteconomia da Universidade Federal do Rio Grande do Norte (UFRN). \\ E-mail: jessicamartins.real@gmail.com \\ Judson Daniel Oliveira da Silva \\ Graduando em Biblioteconomia da Universidade Federal do Rio Grande do Norte (UFRN). \\ E-mail: judsondaniel@hotmail.com \\ Rosa Milena dos Santos \\ Graduanda em Biblioteconomia da Universidade Federal do Rio Grande do Norte (UFRN). \\ E-mail: rosamilena3@gmail.com
}

\section{RESUMO:}

Apresenta o panorama da profissão de bibliotecário no Brasil, destacando a identidade do profissional nos dias atuais. Discorre sobre o histórico da profissão de Bibliotecário no Brasil. Aponta os aspectos relativos à formação do Bibliotecário e seus espaços de atuação. Utiliza, como metodologia pesquisa com levantamento bibliográfico em livros, periódicos e sites. Usa como fonte de pesquisa, documentos institucionais do Ministério da Educação (MEC), de associações e de órgãos representativos da profissão e universidades. Faz levantamento de dados em sites de classificados de emprego e divulgação de concursos, utilizando como argumento de busca a profissão de bibliotecário. Considera que a profissão bibliotecário, apesar de ser uma profissão milenar, mostra-se como uma profissão promissora e com grande diversidade de espaços de atuação.

Palavras-chave: Bibliotecário. Identidade profissional. Espaços de atuação do bibliotecário.

\section{ABSTRACT:}

It presents the panorama of the profession of librarian in Brazil, highlighting an identity of the professional in the present day. Discourse on the history of the profession of Librarian in Brazil. It indicates the aspects related to the formation of the Librarian and his spaces of action. Use, as research methodology with bibliographical survey in books, periodicals and websites. It uses as a research source, institutional documents of the Ministry of Education (MEC), associations and representative bodies of the profession and universities. It surveys data on job classification and job search sites, using as a search 
argument a librarian's profession. It considers that a profession of librarians, despite being an age-old profession, shows itself as a promising profession and a great diversity of spaces of action.

Key-words: Librarian. Professional identity. Workplace of the librarian.

\section{INTRODUÇÃO}

Em maio de 2014 foi promovido pela Associação Brasileira de Profissionais da Informação (ABRAINFO) 1 o "Fórum sobre a formação do profissional da informação: desafio contemporâneo". O evento reuniu coordenadores de cursos de Biblioteconomia, professores, profissionais e estudantes da área para discutir a formação profissional e os problemas vivenciados por esta comunidade. Isto, a fim de que fossem levantadas questões que pudessem subsidiar ações a serem empreendidas no sentido de conferir maior qualidade aos cursos de graduação em Biblioteconomia no Brasil.

Como resultado dessa reunião, foi divulgada uma carta aberta relatando as pautas de discussões bem como as reflexões feitas pelo grupo, dentre as quais destacamos a "Alta evasão e baixa procura nos cursos de Biblioteconomia. Causas e superação". Este é de fato um problema vivenciado por grande parte dos cursos e que, segundo o referido documento, trata-se de um fenômeno que incorre em especial nos cursos ofertados nos horários matutino e vespertino, realidade, portanto, do Curso de Biblioteconomia da UFRN.

$\mathrm{Na}$ referida carta aberta, foram elencadas algumas das possíveis causas desse fenômeno:

[...] falta de identidade do curso e do profissional; pouca relação entre as disciplinas não permite que o aluno tenha uma visão de todo o curso; a autoimagem do profissional pode influenciar na permanência e no ingresso ao curso; muitos alunos entram sem conhecer adequadamente o curso; o mercado não conhece o fazer do bibliotecário; a falta de ações afirmativas do exercício profissional reflete efetivamente na baixa procura e na evasão; alunos adiam a formatura para não perder a remuneração do estágio; alunos usam o curso para se transferir para outros na mesma Universidade, ou seja, a facilidade maior de ingresso no curso o transforma em trampolim para outros cuja concorrência é mais acirrada; desatualização de currículos pode ser uma das causas da evasão; alunos desinteressados, cujo objetivo é apenas o de obter um diploma de curso

\footnotetext{
${ }^{1}$ http://www.abrainfo.org.br/
} 
superior; baixa qualidade da educação básica; a falta de perspectiva de mercado, ou o desconhecimento dos vestibulandos sobre isso, pode ser também causa da baixa procura".(grifo nosso)(ALMEIDA JÚNIOR, 2014²).

Nesta perspectiva e visando contribuir para uma maior divulgação do curso junto a comunidade externa local, foi proposta a realização de pesquisa sobre a profissão para fins de apresentação em feira de extensão da UFRN, a CIENTEC no ano de 2014. Considerando que o evento é visitado por vários seguimentos da sociedade potiguar, em especial escolas de ensino médio, pretendeu-se apresentar o resultado dessa pesquisa como forma de divulgar a profissão e o curso à audiência da feira.

Mesmo configurando-se como uma tarefa milenar, o fazer bibliotecário parece ainda ser uma profissão desconhecida e pouco valorizada por alguns setores da sociedade. Nesse sentido, pretendeu-se apresentar um panorama nacional da profissão, visando destacar a identidade do profissional bibliotecário na atualidade, em especial no contexto brasileiro.

Como metodologia, empreendeu-se uma pesquisa bibliográfica em livros, periódicos e sites, bem como documentos institucionais do Ministério da Educação, de associações e órgãos representativos da profissão e universidades. Além disso, foi realizado levantamento de dados em sites de classificados de emprego e divulgação de concursos, para os quais a profissão de bibliotecário figurou como argumento de busca.

Os conteúdos abordados neste trabalho versam sobre o histórico da profissão no Brasil, aspectos relativos à formação do Bibliotecário e seus espaços de atuação, sobre os quais discorremos a seguir.

\section{FORMAÇÃO ACADÊMICA}

A formação do Bibliotecário se dá através de curso de nível superior, ou seja, bacharelado em Biblioteconomia, com tempo de duração médio de 4 anos. Trata-se de um fazer profissional que remonta a idade antiga, a exemplo da famosa biblioteca de Alexandria. Porém, a educação formal desse profissional só aparece no Século XIX.

Antes da formalização do ensino profissional para formação de Bibliotecários, o trabalho na biblioteca era desenvolvido por pessoas treinadas nas atividades de organizar

\footnotetext{
2 Documento não paginado.
} 
os acervos e atender aos usuários, sendo este último em menos escala dada a restrição de acesso das primeiras instituições. Uma vez demonstrada capacidade de autonomia, as tarefas iam sendo ensinadas em níveis graduais de complexidade. Esse treinamento em geral era realizado por pessoas cuja técnica de trabalho havia adquirido a partir dos vários anos trabalhando nas bibliotecas, cargo que em geral eram ocupados por estudiosos notáveis.

De acordo com Davis Jr. (1994), na medida em que as bibliotecas iam crescendo e seus acervos tornando-se maiores, os bibliotecários também ganhavam notoriedade social e tinha seu fazer cada vez mais voltado a gestão do espaço. Tais pessoas eram responsáveis por arrolar o acervo existente e auxiliar usuários na localização de materiais que necessitavam, o que demandava competências linguísticas e habilidades administrativas que os distinguiam dos demais trabalhadores da biblioteca, em geral escravos educados e escribas.

Somente no contexto do século XIX, em consequência do surgimento da imprensa, que acelerou a produção bibliográfica, da revolução francesa, que ampliou o acesso as bibliotecas, e a revolução industrial, que passou a demandar serviços mais elaborados de informação, é que vão surgir as primeiras escolas de Biblioteconomia, que até então aconteciam em forma de cursos de curta duração de caráter estritamente de treinamento.

Surge então o primeiro curso dedicado a formação de profissionais para organização dos arquivos, fossem documentais ou literários, na França em 1821, École des Chartes, atual École Nationale des Chartes. Mesmo nominalmente voltado a formação de arquivistas paleógrafos, o currículo foi aplicado também para formação bibliotecária e, portanto, considerada a primeira escola de formação de bibliotecários.

O primeiro curso de Biblioteconomia no Brasil foi criado no ano de 1911. As primeiras escolas surgidas no país foram sediadas no Estado de São Paulo e na Biblioteca Nacional, localizada no Rio de Janeiro. O curso ministrado no Rio de Janeiro tinha uma forte influência na área humanística, seguindo os moldes da escola francesa, École des Chartes, e era voltado para os próprios funcionários da Biblioteca Nacional.

Já o curso ministrado em São Paulo recebia influências norte-americanas, com aspectos mais técnicos e precisos, sendo direcionado para os professores, funcionários 
de outras instituições além dos funcionários da própria biblioteca, resultando no aumento do curso nos diversos estados brasileiros.

Somente em 1962 a Biblioteconomia se tornou uma profissão de nível superior por ocasião da aprovação da Lei no 4.084, de 30 de junho de 1962. Esta oficializa a profissão em território nacional ao mesmo tempo em que regulamenta o seu exercício.

Neste contexto surge a necessidade de padronização no ensino do curso de Biblioteconomia, surgindo os currículos mínimos de 1962, alterado depois em 1982. Ambas as propostas geraram descontentamento das instituições por não reconhecerem nas estruturas propostas os interesses de formação específicos de cada região.

Tanto os currículos de 1962 quanto o de 1982, havia disciplinas de caráter humanístico e técnico. Em certa medida, Cesar Castro (2000) atribui isso às influencias norte-americanas e francesas integradas ao currículo dos cursos de Biblioteconomia brasileiros.

Assim, em 2001, foram alteradas as diretrizes curriculares com a proposição de competências gerais e específicas, conferindo assim mais autonomia às instituições para a construção de seus currículos.

\subsection{DIRETRIZES CURRICULARES}

Segundo o Parecer CNE/CES n-492 de 2001, os conteúdos curriculares dos cursos de Biblioteconomia dividem-se em gerais e específicos. Os gerais objetivam a aquisição de conhecimentos basilares a formação humanística da profissão, agregando uma perspectiva social e cultural aos bacharéis. Já os conteúdos específicos visam conferir habilidades de caráter técnico inerentes ao fazer bibliotecário. (MINISTÉRIO DA EDUCAÇÃO, 2001, p. 33).

Consoante aos conteúdos curriculares, as diretrizes do Ministério da Educação, no que se refere às competências e habilidades da área de Biblioteconomia, estabelece que o curso em questão deve desenvolvê-las também nos níveis gerais e específicos. Quanto as gerais, estabelece a: geração de produtos a partir dos conhecimentos adquiridos e divulgá-los; formulação e execução de políticas institucionais; elaboração, coordenação, execução e avaliação de planos, programas e projetos; utilização racional dos recursos disponíveis; desenvolvimento e utilização de novas tecnologias; tradução 
das necessidades de indivíduos, grupos e comunidades nas respectivas áreas de atuação; desenvolvimento de atividades profissionais autônomas, de modo a orientar, dirigir, assessorar, prestar consultoria, realizar perícias, emitir laudos técnicos, pareceres e responder a demandas sociais de informação produzidas pelas transformações tecnológicas que caracterizam o mundo contemporâneo.

No que se refere as competências e habilidades específicas, o referido documento elenca as seguintes: "Interagir e agregar valor nos processos de geração, transferência e uso da informação, em todo e qualquer ambiente; criticar, investigar, propor, planejar, executar e avaliar recursos e produtos de informação; trabalhar com fontes de informação de qualquer natureza; processar a informação registrada em diferentes tipos de suporte, mediante a aplicação de conhecimentos teóricos e práticos de coleta, processamento, armazenamento e difusão da informação; realizar pesquisas relativas a produtos, processamento, transferência e uso da informação.

No Brasil existem atualmente 41 Cursos de Biblioteconomia distribuídos pelos estados da federação, os quais são oferecidos por instituições públicas (estaduais e federais) e privadas, conforme demonstra o quadro abaixo.

Quadro 1 - Cursos de Biblioteconomia ofertados por IES brasileiras

\begin{tabular}{|c|l|l|l|l|l|c|}
\hline $\begin{array}{c}\text { Ano de } \\
\text { Início }\end{array}$ & Instituição(IES) & Nome do Curso & Grau & Modalidade & Região & Categoria \\
\hline 1910 & UNIRIO & BIBLIOTECONOMIA & $\begin{array}{l}\text { Bacharel. / } \\
\text { Licenciat. }\end{array}$ & Presencial & Sudeste & Federal \\
\hline 1942 & UFBA & BIBLIOTECONOMIA & Bacharel. & Presencial & Nordeste & Federal \\
\hline 1945 & $\begin{array}{l}\text { PUC- } \\
\text { CAMPINAS }\end{array}$ & BIBLIOTECONOMIA & Bacharel. & Presencial & Sudeste & Privada \\
\hline 1947 & UFRGS & BIBLIOTECONOMIA & Bacharel. & Presencial & Sul & Federal \\
\hline 1948 & FABCI & BIBLIOTECONOMIA & Bacharel. & Presencial & Sudeste & Privada \\
\hline 1950 & UFMG & BIBLIOTECONOMIA & Bacharel. & Presencial & Sudeste & Federal \\
\hline 1950 & UFPE & BIBLIOTECONOMIA & Bacharel. & Presencial & Nordeste & Federal \\
\hline
\end{tabular}




\begin{tabular}{|c|c|c|c|c|c|c|}
\hline 1963 & UFPA & BIBLIOTECONOMIA & Bacharel. & Presencial & Norte & Federal \\
\hline 1963 & UFF & $\begin{array}{l}\text { BIBLIOTECONOMIA } \\
\text { E DOCUMENTAÇÃO }\end{array}$ & Bacharel. & Presencial & Sudeste & Federal \\
\hline 1965 & UFC & BIBLIOTECONOMIA & Bacharel. & Presencial & Nordeste & Federal \\
\hline 1966 & UNB & BIBLIOTECONOMIA & Bacharel. & Presencial & $\begin{array}{l}\text { Centro- } \\
\text { Oeste }\end{array}$ & Federal \\
\hline 1966 & UFAM & BIBLIOTECONOMIA & Bacharel. & Presencial & Norte & Estadual \\
\hline 1966 & USP & BIBLIOTECONOMIA & Bacharel. & Presencial & Sudeste & Estadual \\
\hline 1968 & UNIFORMG & BIBLIOTECONOMIA & Bacharel. & Presencial & Sudeste & Privada \\
\hline 1969 & UFMA & BIBLIOTECONOMIA & Bacharel. & Presencial & Nordeste & Federal \\
\hline 1969 & UFPB & BIBLIOTECONOMIA & Bacharel. & Presencial & Nordeste & Federal \\
\hline 1973 & UEL & BIBLIOTECONOMIA & Bacharel. & Presencial & Sul & Estadual \\
\hline 1974 & UFSC & BIBLIOTECONOMIA & Bacharel. & Presencial & Sul & Federal \\
\hline 1975 & FURG & BIBLIOTECONOMIA & Bacharel. & Presencial & Sul & Federal \\
\hline 1975 & UFES & BIBLIOTECONOMIA & Bacharel. & Presencial & Sudeste & Federal \\
\hline 1975 & FATEA & BIBLIOTECONOMIA & Bacharel. & Presencial & Sudeste & Privada \\
\hline 1976 & FAINC & BIBLIOTECONOMIA & Bacharel. & Presencial & Sudeste & Privada \\
\hline 1977 & UNESP & BIBLIOTECONOMIA & Bacharel. & Presencial & Sudeste & Estadual \\
\hline 1980 & UFG & BIBLIOTECONOMIA & Bacharel. & Presencial & $\begin{array}{c}\text { Centro- } \\
\text { Oeste }\end{array}$ & Federal \\
\hline 1994 & UFSCAR & $\begin{array}{l}\text { BIBLIOTECONOMIA } \\
\text { E CIÊNCIA DA } \\
\text { INFORMAÇÃO }\end{array}$ & Bacharel. & Presencial & Sudeste & Federal \\
\hline 1997 & UFRN & BIBLIOTECONOMIA & Bacharel. & Presencial & Nordeste & Federal \\
\hline 1999 & UFMT & BIBLIOTECONOMIA & Bacharel. & Presencial & Centro- & Federal \\
\hline
\end{tabular}




\begin{tabular}{|c|c|c|c|c|c|c|}
\hline & & & & & Oeste & \\
\hline 1999 & UFAL & BIBLIOTECONOMIA & Bacharel. & Presencial & Nordeste & Federal \\
\hline 2001 & UDESC & BIBLIOTECONOMIA & Bacharel. & Presencial & Sul & Estadual \\
\hline 2001 & IESF & BIBLIOTECONOMIA & Bacharel. & Presencial & $\begin{array}{c}\text { Centro- } \\
\text { Oeste }\end{array}$ & Privada \\
\hline 2003 & UESPI & BIBLIOTECONOMIA & Bacharel. & Presencial & Nordeste & Estadual \\
\hline 2003 & USP & $\begin{array}{l}\text { CIENCIAS DA INF. E } \\
\text { DA DOC. E } \\
\text { BIBLIOTECONOMIA }\end{array}$ & Bacharel. & Presencial & Sudeste & Estadual \\
\hline 2005 & UNIFAI & BIBLIOTECONOMIA & Bacharel. & Presencial & Sudeste & Privada \\
\hline 2006 & UFCA & BIBLIOTECONOMIA & Bacharel. & Presencial & Nordeste & Federal \\
\hline 2006 & UFRJ & \begin{tabular}{lr}
\multicolumn{2}{l}{ BIBLIOTECONOMIA } \\
E GESTÃO DE \\
UNIDADES & DE \\
INFORMAÇÃO &
\end{tabular} & Bacharel. & Presencial & Sudeste & Federal \\
\hline 2009 & UNIR & BIBLIOTECONOMIA & Bacharel. & Presencial & Norte & Federal \\
\hline 2009 & UFS & $\begin{array}{l}\text { BIBLIOTECONOMIA } \\
\text { E DOCUMENTAÇÃO }\end{array}$ & Bacharel. & Presencial & Nordeste & Federal \\
\hline 2013 & UCS & BIBLIOTECONOMIA & Bacharel. & A Distância & Sul & Privada \\
\hline 2016 & CEUCLAR & BIBLIOTECONOMIA & Bacharel. & A Distância & Variadas & Privada \\
\hline 2016 & FAED & BIBLIOTECONOMIA & Bacharel. & Presencial & Sul & Privada \\
\hline 2016 & $\begin{array}{l}\text { UNOCHAPEC } \\
\text { Ó }\end{array}$ & BIBLIOTECONOMIA & Bacharel. & A Distância & Sul & Privada \\
\hline
\end{tabular}

Fonte: Elaborado pelos autores a partir do site do E-MEC.

A partir da observação do quadro acima podemos afirmar que mesmo sendo pouco conhecido, pela maioria da população, o curso de biblioteconomia apresenta 
relevância social e demanda do mercado de trabalho, haja vista que recentemente foram criados novos cursos em nosso país.

\subsection{PÓS GRADUAÇÃO}

Além de graduação, no Brasil também são ofertados cursos em nível de pósgraduação, lato e stricto sensu, na área de Biblioteconomia e Ciência da Informação. Segundo Oliveira (2011, p.46) "o primeiro curso de pós-graduação stricto sensu na área, em nível de mestrado, foi criado pelo IBICT "que hoje mantém parceria com a UFRJ.

Atualmente, 18 instituições brasileiras ofertam cursos de pós-graduação Stricto Sensu na área de Biblioteconomia e Ciência da Informação, tanto profissional (F) quanto acadêmico (M e M/D), conforme demonstramos a partir do quadro abaixo:

\section{Quadro 2 - Relação dos Cursos de Pós-Graduação Stricto Sensu na área de $\mathrm{Cl}$ no Brasil}

\begin{tabular}{|c|c|c|c|c|}
\hline $\begin{array}{c}\text { Ano de } \\
\text { Início }\end{array}$ & Instituição(IES) & Nome do Curso & Modalidade & Região \\
\hline 1976 & UFMG & CIÊNCIAS DA INFORMAÇÃO & M/D & Sudeste \\
\hline 1978 & UNB & CIÊNCIAS DA INFORMAÇÃO & M/D & Centro-Oeste \\
\hline 1998 & UNESP/MAR & CIÊNCIA DA INFORMAÇÃO & M/D & Sudeste \\
\hline 2000 & UFBA & CIÊNCIA DA INFORMAÇÃO & M/D & Nordeste \\
\hline 2000 & UFSC & CIÊNCIA DA INFORMAÇÃO & M/D & Sul \\
\hline 2006 & USP & CIÊNCIA DA INFORMAÇÃO & M/D & Sudeste \\
\hline 2007 & UFPB/J.P. & CIÊNCIA DA INFORMAÇÃO & M/D & Nordeste \\
\hline 2009 & UFPE & CIÊNCIA DA INFORMAÇÃO & M & Nordeste \\
\hline 2009 & UFF & CIÊNCIA DA INFORMAÇÃO & M/D & Sudeste \\
\hline 2009 & UFRJ / IBICT & CIÊNCIA DA INFORMAÇÃO & M/D & Sudeste \\
\hline 2012 & UNIRIO & BIBLIOTECONOMIA & F & Sudeste \\
\hline
\end{tabular}




\begin{tabular}{|c|c|c|c|c|}
\hline 2012 & UNIRIO & $\begin{array}{r}\text { GESTÃO DE DOCUMENTOS E } \\
\text { ARQUIVOS }\end{array}$ & Sudeste \\
\hline 2012 & UEL & CIÊNCIA DA INFORMAÇÃO & $\mathrm{M}$ & Sul \\
\hline $\mathbf{2 0 1 3}$ & UDESC & GESTÃO DA INFORMAÇÃO & $\mathrm{F}$ & Sul \\
\hline 2015 & UFRN & $\begin{array}{r}\text { GESTÃO DA INFORMAÇÃO E DO } \\
\text { CONHECIMENTO }\end{array}$ & $\mathrm{F}$ & Nordeste \\
\hline 2016 & FCRB & MEMÓRIA E ACERVOS & $\mathrm{F}$ & Nordeste \\
\hline 2016 & UFSCAR & CIÊNCIA DA INFORMAÇÃO & $\mathrm{M}$ & Sudeste \\
\hline 2016 & UFCA & BIBLIOTECONOMIA & $\mathrm{F}$ & Nordeste \\
\hline 2016 & UFC & CIÊNCIA DA INFORMAÇÃO & $\mathrm{M}$ & Nordeste \\
\hline
\end{tabular}

Fonte: Elaborado pelos autores a partir do site da CAPES.

A pós-graduação tem se inserido de forma crescente na formação de profissionais da informação, como forma de educação continuada e atualização profissional. Além disso, a atual política nacional de plano de carreiras e salários, no âmbito do serviço público, tem elevado consideravelmente o número de bibliotecários com formação em níveis de mestrado e doutorado, em especial dos servidores público federais. Nesta perspectiva, percebe-se que, mesmo ainda de forma inexpressiva, vemos surgir a oferta de mestrado profissional, a exemplo das universidades UFRN, FCRB, UFSCAR, UFCA e UFC.

A fim de caracterizar melhor os programas de Pós-graduação na área, foi elaborado um quadro demonstrando as linhas de pesquisa dos programas (QUADRO 3):

Quadro 3 - Relação das linhas de pesquisa dos programas de Pós-Graduação em Cl no Brasil.

\begin{tabular}{|c|c|r|}
\hline Região & Instituição (IES) & \multicolumn{1}{c|}{ Linhas de Pesquisa } \\
\hline \multirow{3}{*}{ Nordeste } & UFBA & $\begin{array}{l}\text { Politicas e tecnologias da informação. } \\
\text { — Produção, circulação e mediação da informação. }\end{array}$ \\
\cline { 2 - 4 } & UFC & $\begin{array}{l}\text { Representação da informação e do conhecimento e } \\
\text { Tecnologia } \\
\text { - Mediação e gestão da informação e do conhecimento }\end{array}$ \\
\hline
\end{tabular}




\begin{tabular}{|c|c|c|}
\hline & UFCA & $\begin{array}{l}\text { - Informação, cultura e memória. } \\
\text { - Produção, comunicação e uso da informação }\end{array}$ \\
\hline & UFPB & $\begin{array}{l}\text { - Informação, memória e sociedade, } \\
\text { - Organização, acesso e uso da informação. } \\
\text { - Ética, gestão e politicas de informação. }\end{array}$ \\
\hline & UFPE & $\begin{array}{l}\text { - Memória da informação cientifica e tecnológica. } \\
\text { - Comunicação e visualização da memória. }\end{array}$ \\
\hline & UFRN & - Gestão da informação e do conhecimento. \\
\hline $\begin{array}{l}\text { Centro- } \\
\text { oeste }\end{array}$ & UNB & $\begin{array}{l}\text { - } \quad \text { Comunicação e mediação da informação. } \\
\text { - Organização da informação. }\end{array}$ \\
\hline \multirow{9}{*}{ Sudeste } & FCRB & $\begin{array}{l}\text { Patrimônio documental: representação, } \\
\text { gerenciamento e preservação de espaços de } \\
\text { memória } \\
\text { - Práticas críticas em acervos: difusão, acesso, uso e } \\
\text { apropriação do patrimônio documental material e } \\
\text { imaterial }\end{array}$ \\
\hline & USP & $\begin{array}{l}\text { - } \quad \text { Apropriação social da informação. } \\
\text { - } \quad \text { Gestão de dispositivos de informação. } \\
\text { - Organização da informação e do conhecimento. }\end{array}$ \\
\hline & UNESP & $\begin{array}{l}\text { - Informação e tecnologia } \\
\text { - } \quad \text { Produção e organização da informação. } \\
\text { - } \quad \text { Gestão, mediação e uso da informação. }\end{array}$ \\
\hline & UFF & $\begin{array}{l}\text { - Informação, cultura e sociedade. } \\
\text { - Fluxos e mediações sócio-técnicas da informação. }\end{array}$ \\
\hline & UFRJ / IBICT & $\begin{array}{l}\text { - Comunicação, organização e gestão da Informação e } \\
\text { do conhecimento. } \\
\text { - Configurações socioculturais, políticas e econômicas } \\
\text { da informação. }\end{array}$ \\
\hline & UNIRIO & $\begin{array}{l}\text { - } \quad \text { Biblioteconomia, cultura e sociedade. } \\
\text { - } \text { Organização e representação do conhecimento. } \\
\text { - } \quad \text { Gestão da informaçãa arquivística. }\end{array}$ \\
\hline & UFMG & $\begin{array}{l}\text { - Memória social, patrimônio e produção do } \\
\text { conhecimento } \\
\text { - } \quad \text { Políticas públicas e organização da informação } \\
\text { - Usuários, gestão do conhecimento e práticas } \\
\text { informacionais }\end{array}$ \\
\hline & UFSCAR & $\begin{array}{l}\text { - Conhecimento e informação para inovação } \\
\text { - Tecnologia, informação e representação }\end{array}$ \\
\hline & UEL & $\begin{array}{l}\text { - Organização e representação da informação e do } \\
\text { conhecimento. }\end{array}$ \\
\hline
\end{tabular}




\begin{tabular}{|c|c|c|}
\hline \multirow{3}{*}{ Sul } & & - Compartilhamento da informação e do conhecimento. \\
\hline & UDESC & $\begin{array}{l}\text { - Gestão de unidades de informação. } \\
\text { - } \quad \text { Informação, memoria e sociedade. }\end{array}$ \\
\hline & UFSC & $\begin{array}{l}\text { - Organização, representação e mediação da } \\
\text { - Informação e do conhecimento. } \\
\text { - Informação, gestão e tecnologia. }\end{array}$ \\
\hline
\end{tabular}

Fonte: Elaborado pelos autores a partir dos sites das universidades analisadas.

A observância do quadro acima permite inferir, ainda que de forma incipiente, que existe uma agenda coerente de pesquisa na área e que se estende por todo o país, em que encontramos recorrência da Memória, Mediação e Gestão.

\section{ATUAÇÃO BIBLIOTECÁRIA}

Com a globalização vivenciada através das tecnologias de informação e comunicação, e a consequente necessidade das pessoas e das organizações de aprender e inovar, sempre em perspectiva crescente, coloca cada vez mais a informação como um insumo necessário para fomentar esse processo. Neste sentido, o profissional da informação, nomeadamente o bibliotecário, tem sido cada vez mais demandado, tendo em vista suas competências no processo de organização e gestão da informação.

A despeito disso, ainda parece ser de senso comum a falsa ideia de que o curso de Biblioteconomia forma higienizadores e arrumadores de livros em bibliotecas, o que denota desconhecimento da profissão e de seus ambientes de atuação.

De fato, as bibliotecas se constituem mercado de trabalho do bibliotecário por excelência. Porém, na atualidade este mercado tem abrangido diferentes instituições e espaços desde que haja necessidade de organização e gestão informacional.

No Brasil a profissão é regulamentada pela Lei Federal ํo 4.084/1962, a qual estabelece que é privativo aos Bacharéis em Biblioteconomia as atividades de organização, gestão e manutenção de bibliotecas e seus serviços. Todavia, a lei no 9.674 de 1998, em seu Art. 33, §3º, concede ao Técnico em Biblioteconomia a possibilidade de exercer tais atividades em bibliotecas públicas de municípios de até mil habitantes e cujo acervo não ultrapasse duzentos exemplares catalogados, desde que o profissional esteja devidamente registrado no respectivo Conselho Regional de Biblioteconomia. 
Nesta perspectiva, e na busca de delinear as características gerais deste mercado foram observados Projetos pedagógicos de cursos de Biblioteconomia no Brasil, tendo em vista que os mesmos caracterizam as competências profissionais demandadas pelo mercado. Além disso, foram verificadas as atividades descritas em ofertas de vagas para bibliotecários veiculadas em sites de classificados e de divulgação de concursos, especificamente o site desenvolvido pelo Bibliotecário Oswaldo Francisco de Almeida Júnior (http://www.ofaj.com.br/) e da PCI Concurso.

Para fins de observar como as escolas de biblioteconomia visualizam o mercado e duas demandas, selecionamos quatro projetos pedagógicos, buscando contemplar as diversas regiões brasileiras. Neste sentido foram utilizados os seguintes PPC's: UFMA (Região Norte), UFPE (Região Nordeste), UFMG (Região Sudeste), UFRSC (Região Sul). A região centro-oeste não foi contemplada dada a indisponibilidade do documento em meio digital.

Figura 1 - Mercado e perfil profissional na perspectiva dos PPCs

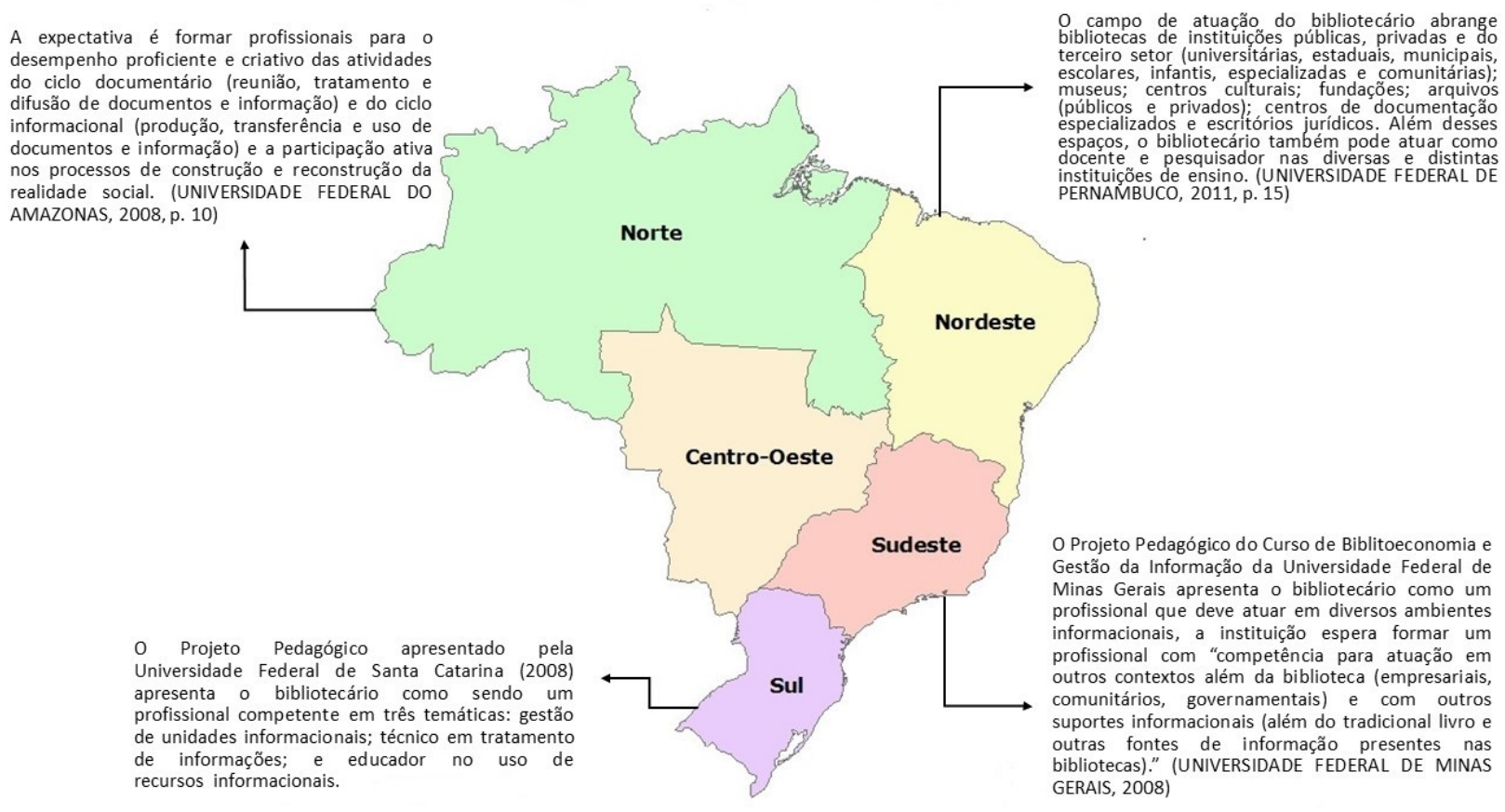

Fonte: Elaborado pelos autores a partir dos sites das universidades analisadas.

A análise dos PPC's mostra a diversidade de espaços passíveis da atuação do Bibliotecário. Percebe-se que há uma preocupação, do ponto de vista da sua formação, 
por oferecer ao mercado de trabalho profissionais aptos para atuar tanto na esfera pública quanto privada. As instituições vão desde as tradicionais bibliotecas como também órgãos vinculados da administração pública, empresas, e indústria e comércio. Além disso, busca-se também atender a demanda por profissionais que atuem nas áreas de ensino e pesquisa.

No que diz respeito as reais demandas de mercado, elaboramos um quadro com descrição de atividades relatadas no site de classificados de oferta de empregos, a partir do qual podemos observar as diferentes atividades desenvolvidas por bibliotecários, corroborando com a ideia de que as bibliotecas consistem em nicho de mercado mas que não se apresenta de forma exclusiva e limitada.

Quadro 4 - Atividades demandadas pelo mercado para o exercício do profissional bibliotecário.

\begin{tabular}{|c|c|c|}
\hline Cargos & Cidades & Descrição das atividades \\
\hline Bibliotecário & Salvador - BA & $\begin{array}{l}\text { Disponibilizar informação em qualquer suporte; gerenciar } \\
\text { unidades como bibliotecas, centros de documentação, } \\
\text { centros de informação e correlatos, além de redes e } \\
\text { sistemas de informação. Tratar tecnicamente e } \\
\text { desenvolver recursos informacionais; disseminar informação } \\
\text { com o objetivo de facilitar o acesso e geração do } \\
\text { conhecimento; desenvolver estudos e pesquisas; promover } \\
\text { difusão cultural; desenvolver ações educativas. Assessorar } \\
\text { nas atividades de ensino, pesquisa e extensão. }\end{array}$ \\
\hline Bibliotecário & $\begin{array}{l}\text { Balneário Gaivota - } \\
\text { SC }\end{array}$ & $\begin{array}{l}\text { Disponibilizar informação; gerenciar unidades como } \\
\text { bibliotecas, centros de documentação, centros de informação } \\
\text { e correlatos, além de redes e sistemas de informação; tratar } \\
\text { tecnicamente e desenvolver recursos informacionais; } \\
\text { disseminar informação com o objetivo de facilitar o acesso e } \\
\text { geração do conhecimento; desenvolver estudos e pesquisas; } \\
\text { promover difusão cultural; desenvolver ações educativas. } \\
\text { Assessorar nas atividades de ensino, pesquisa e extensão. } \\
\text { Prestar os serviços inerentes ao cargo de Bibliotecário na } \\
\text { Administração Pública Municipal. }\end{array}$ \\
\hline Bibliotecário & Cruz Alta - RS & $\begin{array}{l}\text { Classificação e catalogação de documentos, manuscritos, } \\
\text { livros, periódicos e outras publicações; atender aos } \\
\text { leitores, prestando informações, consultando fichários, } \\
\text { indicando estantes, localizando o material desejado, } \\
\text { fazendo reservas ou empréstimos; controlar empréstimos } \\
\text { e devolução de obras, para evitar perdas e manter a } \\
\text { disponibilidade do acervo; organizar e manter organizadas } \\
\text { as obras do acervo, dispondo-as segundo o critério de } \\
\text { classificação e catalogação adotado na Biblioteca; auxiliar } \\
\text { no levantamento de dados estatísticos sobre a utilização } \\
\text { de obras do acervo, para identificar demandas por leitura; } \\
\text { elaborar listagens relativas a livros, documentos, periódicos }\end{array}$ \\
\hline
\end{tabular}




\begin{tabular}{|c|c|c|}
\hline & & $\begin{array}{l}\text { e outras publicações adquiridas pela Biblioteca para } \\
\text { divulgação do acervo junto aos usuários; controlar e } \\
\text { providenciar a manutenção das obras do acervo; integrar } \\
\text { e realizar atividades de sindicância e processos } \\
\text { administrativos; executar outras atribuições afins.. }\end{array}$ \\
\hline Bibliotecário & Tarumirim - MG & $\begin{array}{l}\text { Receber livros, revistas, folhetos e outras publicações, } \\
\text { registrá-las em fichas apropriadas, anotando nome do autor, } \\
\text { editor, data de publicação, série, assunto, colaboradores, } \\
\text { título do assunto e outros dados interessantes, bem como } \\
\text { organizá-los de forma adequada; estabelecer, mediante } \\
\text { consulta aos demais órgãos de ensino e à própria } \\
\text { comunidade, critérios de aquisição e permuta de obras para } \\
\text { a biblioteca; elaborar e executar programas de incentivo ao } \\
\text { hábito de leitura; organizar e manter atualizados os registros } \\
\text { e controles de consultas e consulentes; atender as } \\
\text { solicitações dos leitores e demais interessados, } \\
\text { desenvolvendo e indicando bibliografias e orientando-os } \\
\text { em suas pesquisas; providenciar a aquisição e } \\
\text { manutenção de livros, revistas e demais materiais } \\
\text { bibliográficos; elaborar relatórios mensais, anuais e outros } \\
\text { levantamentos dos serviços executados pela biblioteca; } \\
\text { controlar a devolução dos livros, revistas, folhetos e } \\
\text { outras publicações nos prazos estabelecidos; coordenar e } \\
\text { supervisionar o trabalho de todos os servidores em } \\
\text { atividade na biblioteca; executar outras atribuições afins. }\end{array}$ \\
\hline Bibliotecário & São Paulo - SP & $\begin{array}{l}\text { Realizar recebimento e controle de qualidade de arquivos em } \\
\text { XML e PDF de artigos científicos a serem publicados na base } \\
\text { de dados eletrônica; Normalização de dados utilizados para } \\
\text { geração de índices bibliométricos; Testes de ferramentas, } \\
\text { sistemas e aplicativos; Suporte para editores e prestadores } \\
\text { de serviço. }\end{array}$ \\
\hline Bibliotecário & São Paulo - SP & $\begin{array}{l}\text { Contribuir com as discussões sobre as transformações } \\
\text { conceituais da Biblioteca em curso, considerando a evolução } \\
\text { das tecnologias da informação e comunicação; Realizar } \\
\text { atendimento aos usuários - compreender suas necessidades } \\
\text { para orientar a busca e a seleção de materiais; disseminar o } \\
\text { acervo da Biblioteca; apoiar a pesquisa em catálogos } \\
\text { eletrônicos; controlar empréstimos e devoluções; Apoiar no } \\
\text { processo de novas aquisições de livros e outros materiais } \\
\text { com base nos perfis e interesses da comunidade escolar, } \\
\text { projetos desenvolvidos e novidades do mercado editorial; } \\
\text { Estabelecer parcerias com a equipe pedagógica apoiando-a } \\
\text { no desenvolvimento de projetos de leitura; Apoiar na } \\
\text { promoção e organização de eventos; Classificar e catalogar } \\
\text { documentos e recursos da Biblioteca; Atualizar e organizar o } \\
\text { acervo, considerando as aquisições e descartes; Organizar } \\
\text { materiais do acervo nas estantes. }\end{array}$ \\
\hline Bibliotecário & Silva Jardim - RJ & $\begin{array}{l}\text {-planejar, coordenar ou executar a seleção, o registro, a } \\
\text { catalogação e a classificação de livros e publicações diversas } \\
\text { do acervo da Biblioteca, utilizando regras e sistemas } \\
\text { específicos, para armazenar e recuperar informações e } \\
\text { colocá-las à disposição dos usuários; }\end{array}$ \\
\hline
\end{tabular}




\begin{tabular}{|c|c|c|}
\hline & & $\begin{array}{l}\text {-selecionar, registrar e analisar artigos de jornais, periódicos, } \\
\text { capítulos de livros e informações de especial interesse para } \\
\text { o Município, indexando-os de acordo com o assunto, para } \\
\text { consulta ou divulgação aos interessados; } \\
\text {-organizar fichários, catálogos e índices, utilizando fichas } \\
\text { apropriadas ou processos mecanizados, coordenando sua } \\
\text { etiquetação e organização em estantes, para possibilitar o } \\
\text { armazenamento, a busca e a recuperação de informações; } \\
\text {-estabelecer, mediante consulta aos órgãos de ensino e à } \\
\text { própria comunidade, critérios de aquisição e permuta de } \\
\text { obras literárias, tendo em vista sua utilização pelos alunos } \\
\text { dos estabelecimentos de ensino do Municipio; } \\
\text {-promover campanhas de obtenção gratuita de obras para a } \\
\text { Biblioteca; } \\
\text {-elaborar e executar programas de incentivo ao hábito da } \\
\text { leitura junto à população a aos alunos da rede municipal de } \\
\text { ensino; } \\
\text {-organizar e manter atualizados os registros e os controles de } \\
\text { consultas e consulentes; } \\
\text {-atender às solicitaçães dos leitores e demais interessados, } \\
\text { indicando bibliografias e orientando } \\
\text {-os em suas pesquisas; } \\
\text {-providenciar a aquisição e a manutenção de livros, revistas } \\
\text { e demais materiais bibliográficos; } \\
\text {-elaborar relatórios mensais, anuais e outros levantamentos } \\
\text { dos serviços executados pela Biblioteca; } \\
\text {-controlar a devolução de livros, revistas, folhetos e outras } \\
\text { publicações nos prazos estabelecidos; } \\
\text {-organizar o serviço de intercâmbio, filiando-se a orgãos, } \\
\text { centros de documentação e a outras bibliotecas, para tornar } \\
\text { possivel a troca de informações e material bibliográfico; } \\
\text {-realizar outras atribuições compatíveis com sua } \\
\text { especialização profissional. }\end{array}$ \\
\hline Bibliotecário & Maceió - AL & $\begin{array}{l}\text { Desenvolver a criação, nas unidades escolares do município } \\
\text { e na sede da SEMED, as bibliotecas indispensáveis à } \\
\text { formação do alunado e dos professores; manter os espaços } \\
\text { e acervos bibliográficos catalogados e organizados. }\end{array}$ \\
\hline
\end{tabular}

Fonte: Elaborado pelos autores a partir do site OFAJ (http://www.ofaj.com.br/).

No Brasil, as instituições públicas que mais absorve mão de obra bibliotecária são as de ensino. As demais contratam o profissional para atuação em bibliotecas públicas e escolares. No ano de 2017, só no mês de janeiro, foram 11 (onze) vagas além das opções de cadastro de reserva (CR), conforme mostra o quadro 2.

Quadro 5 - Vagas ofertadas na rede pública em Janeiro/2017.

\begin{tabular}{|c|c|c|}
\hline Instituição & Local & Vagas \\
\hline Universidade Federal da Bahia & Salvador - BA & 5 \\
\hline
\end{tabular}




\begin{tabular}{|c|c|c|}
\hline Prefeitura de Balneário Gaivota & Balneário Gaivota - RS & CR \\
\hline Prefeitura de Cruz Alta & Cruz Alta - RS & 1 \\
\hline Prefeitura de Tarumirim & Tarumirim - MG & CR \\
\hline Prefeitura de Silva Jardim & Silva Jardim - RJ & CR \\
\hline SENAI & Blumenau - SC & 3 \\
\hline Prefeitura de Maceió & Maceió - AL & 1 \\
\hline Escola Americana de Brasília & Brasília - DF & \\
\hline
\end{tabular}

Fonte: Elaborado pelos autores a partir do site OFAJ (http://www.ofaj.com.br/).

Como apresentado nos dados acima, o mercado bibliotecário é bastante extenso e com boa possibilidade de absorção do novo profissional, possibilitando diversas vertentes de atuação.

Além disso, observamos também que o mercado de trabalho representado pelos estados da região nordeste se apresentam de forma mais tradicional, ao passo que na região sudeste são demandas menos convencionais.

\section{NOTAS FINAIS}

Considerando a proposta de apresentar um panorama geral da profissão, entende-se que o objetivo foi alcançado a partir das informações coletadas. Percebe-se que a profissão, mesmo milenar, continua presente na sociedade atual de forma bastante significativa e contribuindo para o desenvolvimento social nos mais diferentes setores.

Para tanto, vem se remodelando para atender a sempre crescente demanda de informação que as sociedades globais vivenciam, tornando-se, cada vez mais, uma carreira promissora e com diversificados espaços de atuação.

Além disso, percebeu-se também uma oferta crescente de qualificação profissional nos diferentes níveis, com presença em quase todo território nacional.

\section{REFERÊNCIAS}


ABED. CENSO EAD BRASIL 2012. Disponível em:

<http://www.abed.org.br/site/pt/midiateca/censo_ead/1193/2013/09/http/www.abed.org.b r/censoead/censoead.br_2012_pt.pdf>. Acesso em: 01 ago. 2014.

BELLUZZO, Regina Célia Baptista. As competências do profissional da informação nas organizações contemporâneas. Revista brasileira de Biblioteconomia e Documentação, Nova Série, São Paulo, v. 7, n. 1, p. 58-73, jan/jun. 2011. Disponível em:< https://infobci.wordpress.com/category/revista-brasileira-de-biblioteconomia-edocumentacao/>. Acesso em: 27 jul. 2014.

FAJARDO, Vanessa. Guia de carreiras: biblioteconomia. Disponível em:< http://g1.globo.com/educacao/guia-de-carreiras/noticia/2011/03/guia-de-carreirasbiblioteconomia.html>. Acesso em: 27 jul. 2014.

FUJITA, Mariângela S.L. Aspectos evolutivos das bibliotecas universitárias em ambiente digital na perspectiva da rede de bibliotecas da UNESP. Inf. \& soc., João Pessoa, v. 15, n. 2, p. 00, jul./dez. 2005. Disponível em : <http://www.ies.ufpb.br/ojs2/index.php/ies/article/view/33/1514>. Acesso em: 08 out. 2009.

HJØRLAND, B. Lybrary and information science: practice, theory, and philosophical basis. In: OLIVEIRA, M. (Org.) Ciência da informação e biblioteconomia: novos conteúdos e espaços de atuação. 2 ed. Belo Horizonte: EDUFMG, 2011.

IBICT/UFRJ. Programa de Pós-Graduação em Ciência da Informação. Disponível em: <http://www.ppgci.ufrj.br/index.php/programa/linhas-de-pesquisas>. Acesso em: 9 ago. 2014.

MINISTÉRIO DA EDUCAÇÃO. Parecer CNE/CES № 492 de 9 de agosto de 2001. disponível em: <http://portal.mec.gov.br/cne/arquivos/pdf/CES0492.pdf>. Acesso em: 12 de julho de 2014.

OLIVEIRA, M.; CARVALHO, G.F.; SOUZA, G.T. Trajetória histórica do ensino da Biblioteconomia no Brasil. Informação e Sociedade: estudos, João Pessoa, v. 19, n. 3, p. 13-24, set./dez. 2009.

SANTOS, Gildenir Carolino; RIBEIRO, Célia Maria. Acrônimos, siglas e termos técnicos: arquivística, biblioteconomia, documentação, informática. Campinas, SP: Átomo, 2003. $277 \mathrm{p}$.

CAPES. Lista de cursos de Pós-graduação em Biblioteconomia. Disponível em: <http://conteudoweb.capes.gov.br/conteudoweb/ProjetoRelacaoCursosServlet?acao=pe squisarles\&codigoArea $=60700009 \&$ descricaoArea $=\&$ descricaoAreaConhecimento $=\mathrm{Cl} \%$ CANCIA+DA+INFORMA\%C7\%C3O\&descricaoAreaAvaliacao=CI\%CANCIAS+SOCIAIS +APLICADAS+|>. Acesso em: 8 ago. 2014. 
MINISTÉRIO DA EDUCAÇÃO. Instituições de Educação Superior e Cursos

Cadastrados. Disponível em: <http://emec.mec.gov.br/>. Acesso em: 8 ago. 2014.

UFPB. Ciência da Informação: programa de pós-graduação. Disponível em:

<http://dci.ccsa.ufpb.br/ppgci/index.php>. Acesso em: 9 ago. 2014.

UFPE. Programa de Pós-graduação em Ciência da Informação. Disponível em: <http://www.ufpe.br/ppgci/index.php?option=com_content\&view=article\&id=300\&ltemid= 175>. Acesso em: 9 ago. 2014.

UNIVERSIDADE FEDERAL DO AMAZONAS. Projeto Pedagógico do Curso de Biblioteconomia. Disponível em: <http://biblioteconomiaufam.jimdo.com/projetopol\%C3\%ADtico-pedag\%C3\%B3gico/>. Acesso em: 5 de jun. de 2015.

UNIVERSIDADE FEDERAL DE MINAS GERAIS. Projeto Pedagógico do Curso de Biblioteconomia e Gestão da Informação. Disponível em:

$<$ http://colgradbiblio.eci.ufmg.br/o-curso/projeto-pedagogico-1>. Acesso em: 5 de jun. de 2015.

UNIVERSIDADE FEDERAL DE PERNAMBUCO. Projeto Pedagógico do Curso de Graduação em Biblioteconomia. Disponível em:

$<$ https://biblioteconomiaufpe.files.wordpress.com/2012/01/projeto-pedagc3b3gico-debiblioteconomia-0406.pdf>. Acesso em: 5 de jun. de 2015.

UNIVERSIDADE FEDERAL DE SANTA CATARINA. Projeto Político Pedagógico do Curso de Biblioteconomia da Universidade Federal de Santa Catarina. Disponível em: <http://www.tccbiblio.paginas.ufsc.br/files/2010/09/projeto_pedagogico2008.doc>. Acesso em: 5 de jun. de 2015.

ALMEIDA JUNIOR, Francisco Oswaldo de. Carta aberta - Fórum a formação do profissional da informação. São Paulo: ABRAINFO, 2014. Disponível em:

<http://www.abrainfo.org.br/sites/default/files/Documentos/CartaAberta_ForumProfission allnfo.pdf $>$. Acesso em: 20 ago. 2014

ALMEIDA JUNIOR, Francisco Oswaldo de. Empregos recentes. Disponível em: <http://www.ofaj.com.br>. Acesso em: 24 fev. 2017.

DAVIS JR., Donald G. Education for Librarianship. In.: WIEGAND, Wayne A.; DAVIS JR., Donald G. Encyclopedia of library history. Florence, KY: Routledge, 1994. p.184185.

ALMEIDA, Neilia Barros Ferreira de; BAPTISTA, Sofia Galvão. Breve histórico da Biblioteconomia brasileira: formação do profissional. In.: CONGRESSO BRASILEIRO DE BIBLIOTECONOMIA, DOCUMENTO E CIÊNCIA DA INFORMAÇÃO, 25., 2013, Florianópolis. Anais eletrônicos... Florianópolis: SC, 2013. Disponível em: <http://portal.febab.org.br/anais/article/view/1508>. Acesso em: 20 ago. 2014. 